\title{
EFEITOS DOS ESCOAMENTOS URBANOS E RURAIS NA QUALIDADE DAS ÁGUAS DO CÓRREGO VERRUGA EM VITÓRIA DA CONQUISTA - BAHIA, BRASIL
}

\author{
Maria Lúcia Pires dos Santos*, José Soares dos Santos, Jarbas Rodrigues dos Santos e Leandra Brito de Oliveira \\ Departamento de Ciências Naturais, Universidade Estadual do Sudoeste da Bahia, Estrada do Bem Querer, km 4, \\ 45083-900 Vitória da Conquista - BA, Brasil
}

Recebido em 9/11/07; aceito em 2/6/08; publicado na web em 5/11/08

\begin{abstract}
EFFECTS OF THE URBAN AND RURAL DRAINAGES IN THE QUALITY OF WATERS OF VERRUGA STREAM IN VITÓRIA DA CONQUISTA - BAHIA, BRAZIL. This study examined the spatial and temporal variations of 13 physico-chemical parameters in water and sediment samples collected along the rural and urban section of Verruga Stream. The metal concentrations were determined by FAAS. The conductivity and the concentration of $\mathrm{Na}^{+}, \mathrm{Cl}^{-}$, and $\mathrm{Ca}^{2+}$ showed the largest variations in the urban area demonstrating that these parameters are appropriate indicators of urban contamination. The application of cluster and principal component analysis showed that the $\mathrm{Cd}^{2+}$ and $\mathrm{Mn}^{2+}$ are associated with the use of fertilizers in the rural area.
\end{abstract}

Keywords: principal component analysis; Verruga Stream; urban activities.

\section{INTRODUÇÃO}

O planejamento inadequado da urbanização na maioria das cidades brasileiras vem ocasionando alterações no ambiente que podem influenciar direta ou indiretamente na qualidade de vida da população. Este processo provoca alterações nos ambientes, tais como desmatamento, impermeabilização do solo, movimentos de terra, alteração da topografia, aterramentos de áreas baixas ou alagadas e a veiculação de poluentes. Em conseqüência, sob certas condições ambientais, as ocupações urbanas podem se tornar importantes fontes de poluição dos recursos hídricos. ${ }^{1,2}$

As fontes de poluição dos rios e córregos que percorrem áreas urbanas e rurais estão associadas ao tipo de uso e ocupação do solo, possuindo características próprias quanto aos poluentes que cada uma delas carrega para as águas naturais (por exemplo, os esgotos domésticos apresentam compostos orgânicos biodegradáveis, nutrientes e bactérias). As indústrias lançam uma variedade maior de contaminantes que estão relacionados com os tipos de matériasprimas e processos utilizados. Além destas fontes pontuais, existem ainda os deflúvios superficiais urbano e agrícola, os quais consistem em fontes difusas. ${ }^{1-5}$

O deflúvio superficial urbano contém todos os poluentes que se depositam na superfície do solo. Já o deflúvio superficial agrícola apresenta características que são influenciadas pelas práticas agrícolas utilizadas em cada região, cuja composição varia de acordo com o período do ano em que se prepara o terreno para o plantio, processa a aplicação de fertilizantes e defensivos, e durante a colheita. ${ }^{5-17}$

O sítio urbano de Vitória da Conquista localiza-se no centro da microbacia do Córrego Verruga. Inicialmente a expansão urbana direcionou-se para as áreas próximas das nascentes e, posteriormente, ao longo do curso de água do córrego, cujo leito se encontra canalizado no percurso que atravessa o centro comercial da cidade.

$\mathrm{O}$ aumento significativo da população, desprovido de um planejamento urbano adequado, favoreceu o aparecimento de uma série de problemas ambientais de características degradadoras e impactantes, e apesar dos problemas provocados por esse crescimento, a cabeceira do córrego encontra-se protegida por uma floresta de vegetação densa.

\footnotetext{
*e-mail: luciapires@uesb.br
}

Entretanto, após o percurso canalizado, o Córrego Verruga começa a receber, em vários pontos ao longo do seu leito, despejos de esgoto sanitário e águas pluviais drenados por um sistema de coleta combinado através de galerias e emissários.

A finalidade deste trabalho foi avaliar os impactos provocados pelos escoamentos urbanos e rurais na qualidade das águas do Córrego Verruga, na cidade de Vitória da Conquista, Bahia. Para isso, foram realizadas medidas de condutividade elétrica, sólidos totais dissolvidos, oxigênio dissolvido e $\mathrm{pH}$ e determinações das concentrações de $\mathrm{Zn}^{2+}, \mathrm{Pb}^{2+}, \mathrm{Cd}^{2+}, \mathrm{Cu}^{2+}, \mathrm{Ca}^{2+}, \mathrm{Mg}^{2+}, \mathrm{Mn}^{2+}, \mathrm{Fe}^{3+}, \mathrm{Na}^{+}$e $\mathrm{K}^{+}$em amostras de água e sedimentos coletadas em pontos distribuídos no percurso urbano, suburbano e rural do Córrego Verruga. Com base na variação diária dos parâmetros $\mathrm{Na}^{+}, \mathrm{K}^{+}, \mathrm{PO}_{4}^{2-} \mathrm{e} \mathrm{Cl}, \mathrm{CE}$ e $\mathrm{pH}$, analisados em amostras de água coletadas nos pontos do percurso urbano (P1, P2 e P3), foi avaliada a influência das atividades urbanas na qualidade das águas do córrego.

\section{PARTE EXPERIMENTAL}

\section{Descrição da área em estudo}

O Córrego Verruga nasce em uma área de reserva florestal localizada no perímetro urbano da cidade de Vitória da Conquista, no sudoeste do estado da Bahia (latitude 14 ${ }^{0} 50$ ' 19" Sul, longitude $40^{\circ} 50^{\prime} 19^{\prime \prime}$ Oeste e altitude de $950 \mathrm{~m}$ ). O clima é típico das zonas de transição, apresentando temperaturas médias anuais de $23{ }^{\circ} \mathrm{C}$ e chuvas de $900 \mathrm{~mm}$. A área total do município é de $3743 \mathrm{~km}^{2}$, com uma população 260 mil habitantes. Nas últimas décadas, o município vem sofrendo um grande incremento populacional, o que demandaria um planejamento urbano adequado no sentido de evitar uma série de problemas ambientais de características que resultem em degradação e impacto ambientais. ${ }^{17}$

Após a nascente, o curso superior do Córrego Verruga flui por uma área metropolitana importante, o sítio urbano de Vitória da Conquista. Inicialmente a expansão urbana direcionou-se para as áreas próximas das nascentes e, posteriormente, ao longo do curso de água do córrego, cujo leito se encontra canalizado no percurso que atravessa o centro comercial da cidade. Apesar dos problemas provocados pelo crescimento urbano, a cabeceira do córrego encontra-se protegida por uma 
floresta de vegetação densa. Entretanto, após o percurso canalizado, o córrego começa a receber em vários pontos ao longo do seu leito, despejos de esgoto sanitário e águas pluviais drenados por um sistema de coleta combinado através de galerias e emissários

O curso médio do Córrego Verruga no seu início sofre um impacto importante ao drenar o efluente de uma estação de tratamento de esgoto (ETE). A seguir percorre áreas suburbanas e rurais, onde a densidade demográfica da região é sensivelmente reduzida, cuja população se dedica à produção agrícola, com destaque para cafeicultura e pecuária.

\section{Procedimento de coleta}

Preliminarmente, realizou-se um estudo amplo no percurso urbano do Córrego Verruga, através de determinações dos níveis de $\mathrm{Na}^{+}, \mathrm{K}^{+}$, $\mathrm{Ca}^{2+}, \mathrm{PO}_{4}^{3-}$ e $\mathrm{Cl}^{-}$e medidas de $\mathrm{pH}$ e condutividade elétrica em amostras de água coletadas diariamente por um período de 11 dias, em 3 pontos do curso superior do Córrego. Com a finalidade de avaliar a variação das concentrações das espécies químicas, os pontos de coleta foram distribuídos da seguinte forma: P1 (nascente do córrego), P2 (zona de recebimento das águas pluviais e esgoto sanitário) e P3 (drenagem do efluente da ETE), conforme mostra a Figura 1.

Posteriormente, para avaliar a dinâmica do processo de salinização e os impactos provocados pelas atividades urbanas e rurais foram realizadas análises das principais espécies químicas dissolvidas nas águas superficiais $\left(\mathrm{Na}^{+}, \mathrm{K}^{+}, \mathrm{Ca}^{2+}\right.$ e $\left.\mathrm{Mg}^{2+}\right)$, nutrientes minerais $\left(\mathrm{Fe}^{3+}\right.$, $\mathrm{Mn}^{2+}, \mathrm{Cu}^{2+} \mathrm{e} \mathrm{Zn}^{2+}$ ) e elementos tóxicos provenientes das atividades agrícolas e urbanas $\left(\mathrm{Pb}^{2+} \mathrm{e} \mathrm{Cd}^{2+}\right)$ em amostras de água e sedimentos coletadas nos 3 pontos da área urbana (P1, P2 e P3) e 4 pontos da zona rural (P4, P5, P6 e P7). Os pontos da zona rural foram incluídos para avaliar a poluição difusa provocada pelas atividades agrícolas, perfazendo um total de 7 pontos distribuídos desde a nascente do córrego (P1) passando pela zona urbana e semi-urbana (P2 e P3) até a serra do Marçal (P7), conforme indicado na Tabela 1 e Figura 1.

Devido à variação de importantes parâmetros reguladores da dinâmica das espécies químicas nestes corpos de água, o planejamento para coleta teve como base a distribuição irregular de chuvas na região. As campanhas para coletas foram realizadas seguindo o cronograma: período seco (outubro), início da estação chuvosa (novembro) e final da estação chuvosa (abril).

Para se evitar a introdução de contaminantes superficiais, as

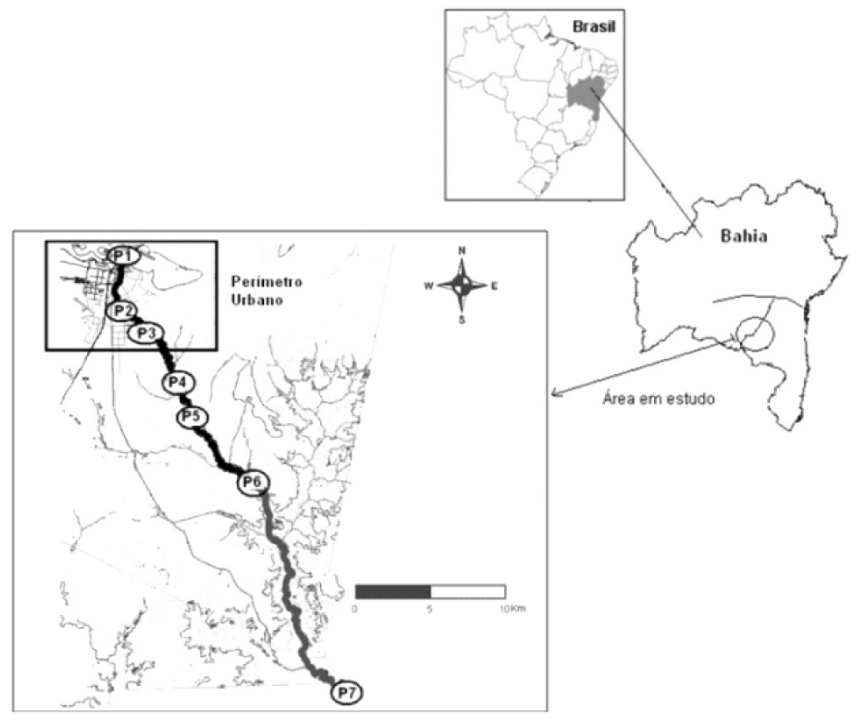

Figura 1. Córrego Verruga e os respectivos pontos de coleta
Tabela 1. Pontos de amostragem e suas características

\begin{tabular}{|c|c|c|c|}
\hline Ponto & Área & Nome do local & Uso de solo \\
\hline $\mathrm{P} 1$ & Urbana & Poço escuro & $\begin{array}{c}\text { Parque Municipal } \\
\text { (reserva de Mata Atlântica) }\end{array}$ \\
\hline P2 & Urbana & Horto Florestal & $\begin{array}{l}\text { Zona de drenagem das águas } \\
\text { pluviais e esgoto bruto }\end{array}$ \\
\hline P3 & $\begin{array}{l}\text { Semi- } \\
\text { urbana }\end{array}$ & $\begin{array}{l}\text { Comunidade } \\
\text { Bem Querer }\end{array}$ & $\begin{array}{c}\text { Residências, agricultura, } \\
\text { pecuária e drenagem do } \\
\text { efluente da (ETE) }\end{array}$ \\
\hline P4 & Rural & $\begin{array}{l}\text { Fazenda } \\
\text { Amaralina }\end{array}$ & $\begin{array}{l}\text { Agricultura, pecuária e drena- } \\
\text { gem do efluente da (ETE) }\end{array}$ \\
\hline P5 & Rural & $\begin{array}{l}\text { Fazenda } \\
\text { Amaralina }\end{array}$ & $\begin{array}{l}\text { Agricultura e pecuária, } \\
\text { zona de aeração devido à } \\
\text { existência de quedas d'água }\end{array}$ \\
\hline P6 & Rural & $\begin{array}{c}\text { Fazenda } \\
\text { Bem Querer }\end{array}$ & Cafeicultura e pecuária \\
\hline P7 & Rural & $\begin{array}{c}\text { Serra do } \\
\text { Marçal }\end{array}$ & $\begin{array}{l}\text { Pecuária, próximo à rodovia } \\
\text { estadual BA-262 (fluxo } \\
\text { do córrego por grandes cas- } \\
\text { catas, devido a desnível de } \\
\text { aproximadamente } 100 \mathrm{~m} \text { ) }\end{array}$ \\
\hline
\end{tabular}

amostras de água foram coletadas a uma distância de $2 \mathrm{~m}$ da margem, mergulhando frascos de polietileno até uma profundidade de $50 \mathrm{~cm}$. A seguir o frasco foi direcionado de modo que a boca ficasse no sentido contrário à correnteza. Finalmente, inclinou-se o frasco lentamente para cima a fim de permitir a saída do ar e o conseqüente enchimento com água. Após a retirada do frasco do corpo de água, desprezou-se uma pequena porção da amostra, deixando um espaço vazio suficiente que permitisse a homogeneização da amostra; a seguir, as amostras foram preservadas pela adição de ácido nítrico até $\mathrm{pH}=2$. As amostras destinadas à determinação de $\mathrm{pH}, \mathrm{CE}, \mathrm{PO}_{4}^{2-} \mathrm{e}$ $\mathrm{Cl}^{-}$foram preservadas com gelo e mantidas a aproximadamente 4 ${ }^{0} \mathrm{C}$ até a análise. As medidas de oxigênio dissolvido (OD) foram realizadas nos locais de coleta.

As amostras de sedimento foram coletadas a uma profundidade média de $2 \mathrm{~m}$, com auxílio de um cano de PVC de $50 \mathrm{~mm}$ de diâmetro e $3 \mathrm{~m}$ de comprimento. A seguir, foram armazenadas em sacos de polietileno e mantidas a uma temperatura abaixo de $0{ }^{\circ} \mathrm{C}$.

\section{Reagentes e soluções}

Para a determinação de metais, as soluções estoque foram preparadas a partir de soluções padrão (Accustandart/SpecSol) de concentração $1000 \mathrm{mg} \mathrm{mL}^{-1} \mathrm{e}$ água deionizada purificada através do sistema Milli-Q (Millipore) até alta pureza (resistividade $18 \mathrm{M} \Omega$ $\mathrm{cm}^{-1}$ ) e acondicionadas em frascos de polietileno pré-lavados com $\mathrm{HNO}_{3} 10 \%$. As soluções de trabalho foram obtidas por diluição das soluções estoque. Um branco foi preparado com $\mathrm{HNO}_{3} 1 \%$ em água deionizada e estocado da mesma forma. Para obtenção das curvas analíticas, as soluções de referência foram preparadas por diluição serial das soluções estoque $1000 \mathrm{mg} \mathrm{mL}^{-1}$ em água deionizada.

\section{Preparo das amostras de sedimento}

Após a remoção de pedaços de plantas e pequenas pedras, as amostras de sedimento foram secas a $60{ }^{\circ} \mathrm{C}$, trituradas suavemente $\mathrm{e}$ homogeneizadas. Devido à afinidade dos elementos metálicos pela fração mais fina dos sedimentos, as amostras foram peneiradas a uma granulometria de $63 \mu \mathrm{m}$. A seguir, um procedimento de extração seletiva foi aplicado para avaliar a disponibilidade dos metais. 
A fração disponível corresponde à porção do metal no sedimento que se encontra suficientemente livre para interagir com a biota aquática. Como a disponibilidade dos íons metálicos nos sedimentos é governada pelos equilíbrios químicos dos íons na fase sólida e em solução, as reações de adsorção são importantes para avaliar a sua disponibilidade e mobilidade no meio. Para extrair metal disponível, uma alíquota de sedimento é agitada na presença de uma solução aquosa que contém uma substância química capaz de deslocar a fração do elemento que pode interagir com a biota aquática. Os sais neutros moderados, como acetato de amônio e cloreto de potássio, são largamente utilizados para esse fim.

Neste trabalho utilizou-se o método de fracionamento por extração química em três etapas: fração solúvel ( $1 \mathrm{~g}$ de sedimento foi tratado com $10 \mathrm{~mL}$ de $\mathrm{H}_{2} \mathrm{O}$ ultra pura e submetido à agitação por $1 \mathrm{~h}$ ), fração trocável $(1 \mathrm{~g}$ de sedimento foi tratado com $10 \mathrm{~mL}$ de $\mathrm{CH}_{3} \mathrm{COONH}_{4} 1 \mathrm{~mol} \mathrm{~L}^{-1}$ e submetido à agitação por $30 \mathrm{~min}$ ) e a fração residual pelo método USEPA-3050 (0,5 $\mathrm{g}$ de sedimento foi tratado com $\mathrm{HNO}_{3}+\mathrm{HCl}+\mathrm{H}_{2} \mathrm{O}_{2}$ e aquecimento em blocodigestor). Este procedimento é utilizado para extrair a parcela dos contaminantes adsorvidos nos sedimentos que não estão prontamente disponíveis para os organismos aquáticos.

Após cada etapa de extração, a separação foi feita por filtração. O sobrenadante foi diluído a volume final de $25 \mathrm{~mL}$ com água deionizada ultrapura (18 $\mathrm{M} \Omega \mathrm{cm}^{-1}$ de resistividade especifica); posteriormente, os extratos foram transferidos para frascos de polietileno de $100 \mathrm{~mL}$ e armazenados a $4{ }^{\circ} \mathrm{C}$ até o momento da análise. As frações extraídas foram calculadas por diferença das concentrações das etapas anteriores, pois cada fração obtida foi extraída a partir de uma nova amostra. Durante todo o processo de extração foi sempre processado um controle (branco) das amostras. ${ }^{18-20}$ A solução do branco, contendo todos os reagentes exceto o analito, foi preparada e tratada segundo o mesmo procedimento descrito para as amostras de sedimento.

\section{Procedimentos analíticos}

As determinações dos elementos $\mathrm{Na}, \mathrm{K}, \mathrm{Ca}, \mathrm{Mg}, \mathrm{Zn}, \mathrm{Cd}, \mathrm{Cu}$ e Ni nas amostras de água e de sedimento foram realizadas empregando um espectrômetro de absorção atômica por chama (FAAS), modelo AAnalyst 200 (USA) equipado com corretor de fundo de deutério. A resposta do instrumento foi conferida periodicamente com soluções padrões de concentração conhecida. O sistema de aquisição de dados foi gerenciado por microcomputador acoplado ao espectrômetro de absorção atômica e como fonte de radiação foi empregada lâmpada de cátodo oco dos respectivos metais.

As análises físico-químicas foram realizadas utilizando-se pHmetro de bancada Digimed, modelo DM 20; condutivímetro de bancada CAAL, modelo MCA-150; medidor de oxigênio dissolvido digital portátil, Homis - modelo 914; turbidímetro digital de bancada, modelo TD-200.

\section{Análise estatística}

Devido à existência de diferentes fatores (concentração por evaporação, poluição urbana, poluição rural e inundação) que poderiam afetar a mobilidade dos metais nos ambientes aquáticos, aplicou-se a análise por agrupamentos hierárquicos (HCA) e a análise por componentes principais (PCA) nos resultados das análises das amostras de água e sedimento, visando desenvolver o estudo das variáveis geoquímicas capazes de promover uma caracterização da hidroquímica e estabelecer os fatores fundamentais que governam o comportamento geral dos recursos hídricos em estudo.

Na HCA, o quadrado da distância euclidiana e o coeficiente de semelhança foram usados para agrupar os casos em clusters, base- ando-se na proximidade ou semelhança dos mesmos. Neste estudo os dados foram normalizados (Z-scores) e tratados pelo método de ligação de Ward.

A PCA é uma técnica muito aplicada para reconhecimento de padrão, sendo possível explicar a discrepância de um grande número de variáveis correlacionadas. Indica também as associações entre variáveis, reduzindo a dimensão do número de dados. A partir da PCA podem-se extrair os autovalores e os autovetores da matriz de covariância de um grupo de variáveis originais. As componentes principais (PCs) são as variáveis não correlacionadas, obtidas multiplicando-se as variáveis correlacionadas originalmente com os autovetores (loadings). Os autovalores dos PCs são as medidas das discrepâncias associadas à participação das variáveis originais nas PCs e são determinados pelos loadings. Os elementos de transformação das novas variáveis são chamados de escores. ${ }^{21-24}$ A PCA foi utilizada para se obter uma redução da dimensão dos dados, conservando a maior parte das informações estatísticas úteis presentes nos dados originais. Todas as operações matemáticas e estatísticas foram realizadas com auxílio dos programas Excel 2003 e SPSS 12.0 (Statistical Package for Social Sciences).

\section{RESULTADOS E DISCUSSÃO}

Os resultados foram divididos em duas partes distintas; na primeira etapa realizou-se um estudo preliminar em amostras de água coletadas diariamente em três pontos da área urbana. Na segunda, incorporou-se ao estudo mais 4 pontos de amostragens localizados na zona rural, onde foram avaliadas amostras de água e de sedimento coletadas no período seco (outubro), início da estação chuvosa (novembro) e final da estação chuvosa (abril) em 3 pontos da área urbana e 4 da zona rural.

\section{Efeitos do escoamento urbano na qualidade das águas do Córrego Verruga (estudo preliminar)}

Durante o processo de urbanização, a construção da infraestrutura, como ruas, calçadas, estruturas comercias e residenciais, normalmente é projetada para drenar as águas da chuva e carregálas para fora do perímetro das cidades através de canais superficiais existentes, como os fluxos dos rios e córregos. As águas de chuva que fluem sobre as cidades carregam poluentes que podem deteriorar a qualidade dos recursos hídricos superficiais. Tipicamente nas águas das enxurradas urbanas são encontrados elementos traços como, por exemplo, chumbo $(\mathrm{Pb})$, zinco $(\mathrm{Zn})$ e cobre $(\mathrm{Cu})$, hidrocarbonetos policíclicos aromáticos (HPA) e sais solúveis.

A Tabela 2 apresenta os valores médios, mínimos e máximos das concentrações dos íons $\mathrm{Na}^{+}, \mathrm{K}^{+}, \mathrm{Ca}^{2+}, \mathrm{PO}_{4}{ }^{3-}, \mathrm{Cl}^{-}$e medidas de $\mathrm{pH}$ e condutividade elétrica das amostras de água coletadas diariamente em 3 pontos do Córrego Verruga localizados no perímetro urbano durante 11 dias. Os parâmetros que apresentaram a maior variação em suas concentrações foram o $\mathrm{Na}^{+}$e o $\mathrm{Cl}^{-}(16,41-75,74$ e 11,34-162,60 mg $\mathrm{L}^{-1}$, respectivamente), refletindo na variação da salinidade observada pela medida de condutividade elétrica $\left(68,10-933,00 \mu \mathrm{S} \mathrm{cm}^{-1}\right)$.

A partir da análise de agrupamentos (cluster) aplicada entre as variáveis $\mathrm{Na}^{+}, \mathrm{K}^{+}, \mathrm{Ca}^{2+}, \mathrm{PO}_{4}^{3-}, \mathrm{Cl}^{-}, \mathrm{pH}$ e $\mathrm{CE}$, para as amostras de água, obteve-se o dendrograma apresentado na Figura 2. A técnica de agrupamento hierárquico é utilizada quando se deseja explorar as similaridades entre as variáveis, interligando as amostras por suas associações e produzindo um dendrograma de amostras semelhantes, agrupadas entre si segundo as variáveis escolhidas. Quanto menor for a distância entre os pontos, maior será a semelhança entre as amostras. Neste trabalho, os dados foram normalizados pela transformação ( $Z$ scores) e tratados pelo método da variância mínima (Ward method), 
Tabela 2. Valores médios, mínimos e máximos dos parâmetros químicos estudados nas amostras coletadas nos pontos P1, P2 e P3 durante 11 dias

\begin{tabular}{lccrrr}
\hline Variável & Unidade & Mínimo & Máximo & Médio & Desvio Padrão \\
\hline $\mathrm{pH}$ & ---- & 6,15 & 7,57 & 6,94 & 0,42 \\
$\mathrm{CE}$ & $\mu \mathrm{S} \mathrm{cm}^{-1}$ & 68,10 & 933,00 & 525,59 & 354,74 \\
$\mathrm{Na}^{+}$ & $\mathrm{mg} \mathrm{L}^{-1}$ & 16,41 & 75,74 & 50,18 & 25,52 \\
$\mathrm{~K}^{+}$ & $\mathrm{mg} \mathrm{L}^{-1}$ & 0,10 & 22,64 & 12,73 & 9,24 \\
$\mathrm{Ca}^{2+}$ & $m \mathrm{mg} \mathrm{L}^{-1}$ & 2,40 & 27,20 & 15,62 & 9,23 \\
$\mathrm{PO}_{4}^{2-}$ & $m \mathrm{mg} \mathrm{L}^{-1}$ & 0,16 & 1,30 & 0,62 & 0,24 \\
$\mathrm{Cl}^{-}$ & $m \mathrm{mg} \mathrm{L}^{-1}$ & 11,34 & 162,60 & 95,02 & 64,66 \\
\hline
\end{tabular}

no qual a formação dos agrupamentos em cada estágio da hierarquia é avaliada pela soma dos quadrados dos desvios em relação ao centro de gravidade dos grupos.

Dois grupos distintos, que se ligam a um nível de distância de 25 podem ser observados no dedrograma da Figura 2. O primeiro grupo denominado de zona de maior estabilidade engloba todas as amostras coletadas no ponto P1 (nascente do Córrego Verruga). Dentro desse agrupamento, observa-se a formação de dois subgrupos que estão ligados entre si a um nível de distância 2, o que indica uma grande similaridade entre eles. As amostras dessa região caracterizam-se por apresentar os mais baixos níveis de concentração das espécies estudadas e por não sofrerem variações significativas em suas concentrações, mesmo em dias chuvosos. Já o segundo grupo denominado de zona de menor estabilidade é formado pelo conjunto de amostras coletadas nos pontos P2 e P3. Nesse agrupamento foi observada a formação de dois subgrupos ligados a um nível de distância 5. As amostras dessa região caracterizam-se por apresentar nos finais de semana variações significativas nos níveis dos parâmetros estudados.

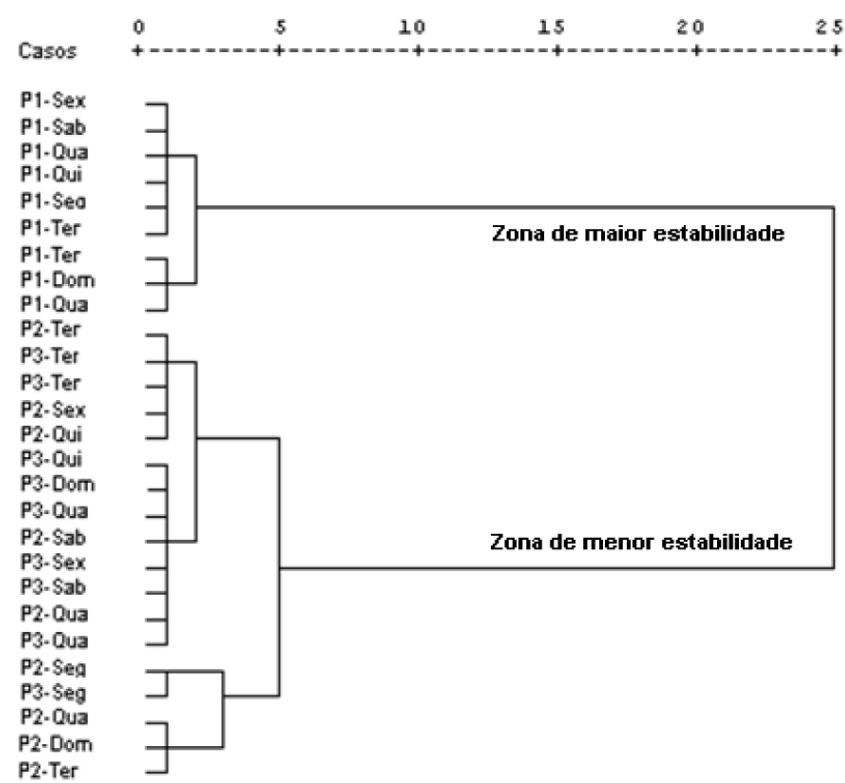

Figura 2. Dendrograma de análise de cluster entre variáveis nas amostras de água coletadas durante 11 dias no perímetro urbano do Córrego Verruga

A influência da atividade urbana na qualidade das águas do Córrego Verruga evidencia-se com base na redução dos teores de $\mathrm{Na}^{+}, \mathrm{Cl}^{-} \mathrm{e}$ medidas de condutividade elétrica observadas nas amostras coletadas às segundas-feiras nos pontos $\mathrm{P} 2 \mathrm{e} \mathrm{P} 3$, quando comparadas com as coletas realizadas nos demais dias da semana, conforme mostrado na Figura 3. O declínio dos valores das concentrações na segunda-feira é um reflexo da redução da drenagem dos resíduos urbanos, provocada pela diminuição do tráfego de pessoas e veículos no centro comercial da cidade que ocorre nos finais de semana.

Com relação ao ponto $\mathrm{P} 1$, pode-se observar que os teores de $\mathrm{Na}^{+}, \mathrm{Cl}^{-}$e as medidas de condutividade elétrica avaliados nas 11 amostras coletadas nos diferentes dias da semana apresentaram-se concordantes. Esse fenômeno indica que a nascente do Córrego Verruga se encontra protegida, devido à estabilidade das concentrações dos parâmetros avaliados, mesmo com as variações sazonais que ocorreram durante o período de amostragem.

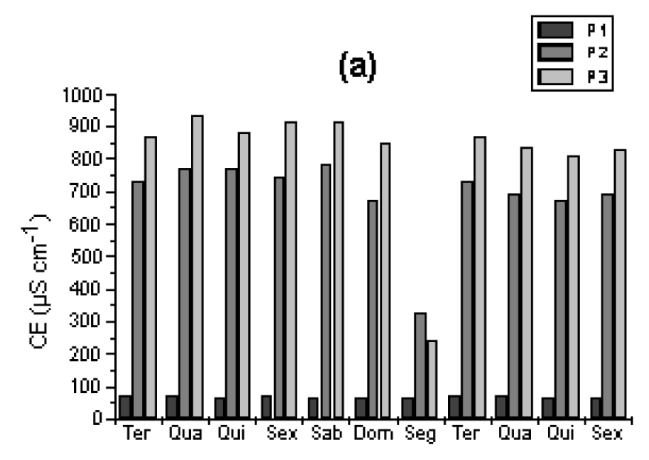

(b)

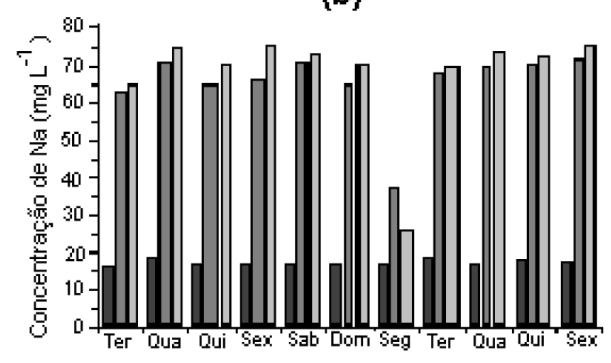

(c)

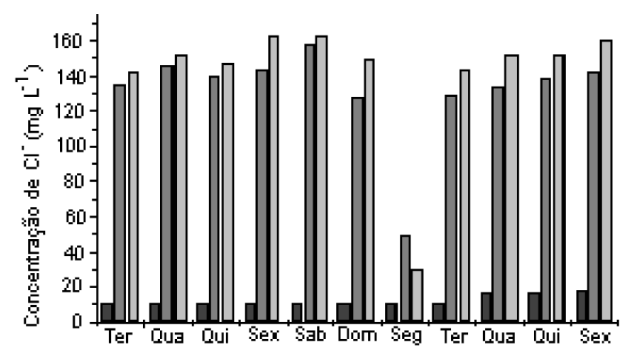

Figura 3. Distribuição da condutividade elétrica (a), concentração de sódio (b) e cloreto (c) no perímetro urbano do Córrego Verruga durante 11 dias 
Efeitos das atividades urbanas e rurais na qualidade das águas do Córrego Verruga

Nas amostras de água coletadas em out/2005 (período seco), abr/2006 (final do período chuvoso) e nov/2006 (período chuvoso), em pontos distribuídos na zona urbana e rural, realizaram-se as medidas de $\mathrm{pH}$, temperatura, oxigênio dissolvido (OD), condutividade elétrica (CE), sólidos totais dissolvidos (STD) e as determinações das concentrações de $\mathrm{Ca}, \mathrm{Mg}, \mathrm{Na}, \mathrm{K}, \mathrm{Cu}, \mathrm{Zn}, \mathrm{Cd}, \mathrm{Ni}, \mathrm{Mn}$ e Fe.

Entre os metais analisados, apenas cádmio e chumbo apresentaram valores de concentração acima do limite máximo estabelecido pela Resolução CONAMA 20/86 para águas de classe 2 (0,001 mg $\mathrm{L}^{-1}$ para $\mathrm{Cd}$ e $0,03 \mathrm{mg} \mathrm{L}^{-1}$ para $\mathrm{Pb}$ ). O Córrego Verruga foi considerado de classe 2, com base no artigo 20 dessa Resolução, que remete para essa classe todos os corpos de água doce que não possuem estudos de enquadramento.

A matriz de semelhança dos coeficientes de correlação usados para análise de agrupamentos entre variáveis e o dendrograma da Figura 4 discriminam a formação de dois grandes grupos, denominados G1 e G2, que estão separados de acordo com a qualidade das águas e se ligam a um nível de distância de 25 . Nota-se a presença de 3 subgrupos dentro do agrupamento denominado G1. Esses subgrupos são mais similares entre si, estão ligados a um nível de distância de 14, separados em função do período de amostragem (períodos chuvoso, seco e final do período chuvoso) e agrupam as amostras dos pontos P2, P3, P4, P5 e P6 que apresentam os níveis mais elevados de concentrações para os parâmetros estudados. O agrupamento G2 é formado pelas amostras coletadas nos 3 períodos diferentes nos pontos P1 e P7 (nascente do Córrego Verruga e Serra do Marçal, respectivamente), locais que apresentaram os menores valores de concentração das espécies estudadas. As concentrações de $\mathrm{Ca}, \mathrm{Mg}$, $\mathrm{Na}, \mathrm{K}, \mathrm{Cu}, \mathrm{Zn}, \mathrm{Cd}, \mathrm{Fe}, \mathrm{Mn}$ e Ni, medidas de $\mathrm{pH}$, temperatura, OD, CE e STD apresentaram concordância nos 3 períodos de amostragem, para os 2 pontos de coleta, demonstrando que a qualidade das águas da nascente (P1) e da Serra do Marçal (P7) se encontra preservada. As baixas concentrações das espécies avaliadas nas águas coletadas na Serra do Marçal indicam que neste ponto o processo de autodepuração do Córrego Verruga começa a ocorrer. Isso pode ser atribuído à aeração natural provocada pelas quedas d'água formadas no local.

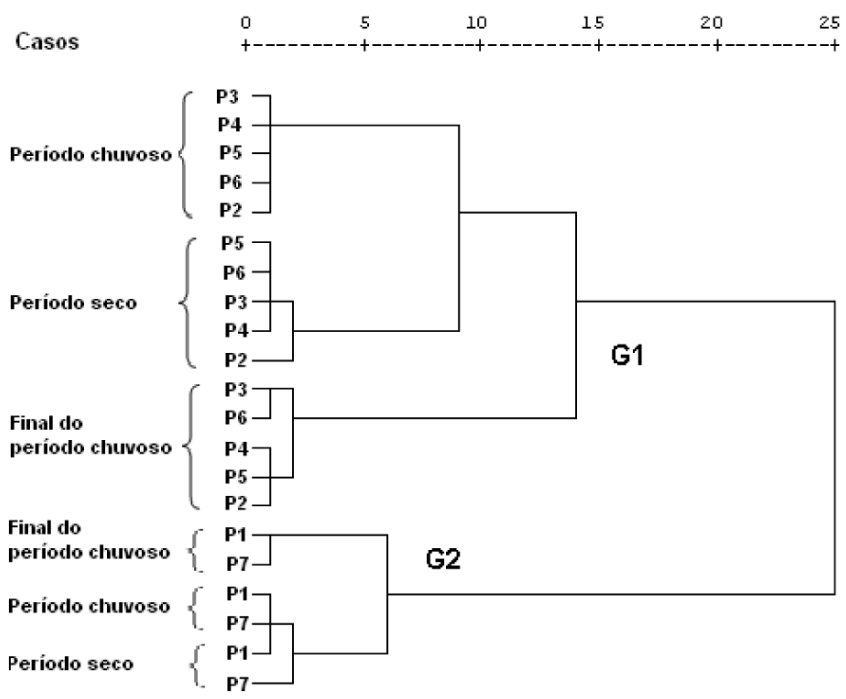

Figura 4. Dendrograma de análise de cluster entre variáveis nas amostras de água coletadas em out/2005, abr/2006 e nov/2006, em pontos distribuídos na zona urbana e rural do Córrego Verruga

\section{Teores de Na, K, Ca, Mg, Mn, Cu, Zn, Cd e Fe nas frações do} sedimento

Devido à importância ambiental das frações que poderiam estar mais facilmente disponíveis na fase líquida e em equilíbrio com a coluna d'água, foram realizadas extrações dos metais nas frações solúveis, disponíveis e residuais nas amostras de sedimento coletadas em out/2005, abr/2006 e nov/2006 nos pontos da área urbana e rural do Córrego Verruga. A Tabela 3 apresenta os valores das concentrações de $\mathrm{Na}, \mathrm{K}, \mathrm{Ca}, \mathrm{Mg}, \mathrm{Mn}, \mathrm{Cu}, \mathrm{Zn}, \mathrm{Cd}$ e Fe determinadas nas três frações. $\mathrm{Na}$ fração solúvel em água (extraída com água deionizada ultrapura), foram detectados teores dos 9 elementos avaliados, inclusive os metais pesados $(\mathrm{Cu}, \mathrm{Zn}$ e $\mathrm{Cd})$ que apresentaram concentrações máximas de 0,$04 ; 0,33$ e $0,37 \mu \mathrm{g} \mathrm{g}^{-1}$. Nesta fração são detectados os metais em forma de íons solúveis que podem ser facilmente disponibilizados para a coluna d'água. $\mathrm{Na}$ fração trocável (extraída com $\mathrm{CH}_{3} \mathrm{COONH}_{4}$ ), com exceção do cobre que não foi detectado, observou-se um aumento significativo nas concentrações dos elementos avaliados. Entre os metais pesados destaca-se o cádmio, que apresentou um incremento de aproximadamente três vezes quando comparado com a fração solúvel. Nesta fração são detectados os metais em forma de íons trocáveis que podem ser facilmente liberados dos sistemas aquáticos por pequenas mudanças ambientais. Já na fração residual (extraída

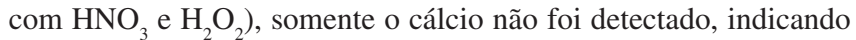
que este elemento, ao contrário dos demais elementos avaliados, está quase que totalmente associado às ações antropogênicas.

\section{Avaliação espacial e temporal dos metais nos sedimentos}

A Tabela 4 apresenta as percentagens dos metais solúveis (parcela extraída com água ultrapura) no sedimento em relação aos teores residuais (parcela extraída com o procedimento USEPA-3050), calculada com base na Equação 1.

$\%$ Metal solúvel $=\frac{\text { fração solúvel em água }}{\text { fração residual }} \times 100$

Nos sedimentos coletados em outubro de 2005 (período seco) e abril de 2006 (final do período chuvoso) não foram detectados teores dos metais estudados na parcela solúvel, com exceção do Fe que foi detectado nas frações solúveis em percentuais extremamente baixos nas amostras dos pontos P5 e P6 coletadas no período seco $(0,04$ e $0,07 \%$, respectivamente) e nas dos pontos P6 e P7 coletadas no final do período chuvoso ( 0,01 e $0,04 \%$, respectivamente). Entretanto, na amostragem de novembro de 2006 (período chuvoso), ao contrário do que ocorreu com as amostras coletadas nos demais períodos, destacam-se os altos teores dos metais encontrados nas frações solúveis dos sedimentos, especialmente para $\mathrm{Cu}$, que foi detectado apenas nas frações solúveis do sedimento nos pontos P3, P4 e P6. O mesmo foi observado para Zn nos sedimentos dos pontos P4 e P5. Já no ponto P3 foi detectada uma parcela menor, porém significativa de $\mathrm{Zn}$ na fração solúvel, 78,57\%. Parcelas significativas de Mn e Cd também foram detectadas nas frações solúveis de todas as amostras de sedimentos coletadas no período chuvoso. Tal discrepância pode ser atribuída ao grande volume de chuvas ocorrido na região (em torno de 182,7 $\mathrm{mm}$ ), que drenou resíduos de $\mathrm{Cu}, \mathrm{Zn}, \mathrm{Mn}$ e Cd provenientes de ações antropogênicas, como o uso de fertilizantes inorgânicos na zona rural e resíduos carregados pelo deflúvio superficial urbano.

\section{Análises de componentes principais (PCA)}

Para evitar equívocos na classificação, provocados pelas diferentes ordens de grandeza existentes entre as variáveis, inicialmente 
Tabela 3. Valores das concentrações dos metais $\left(\mu \mathrm{g} \mathrm{g}^{-1}\right)$ determinadas nas frações dos sedimentos extraídos com água ultrapura, acetato de amônio e procedimento EPA-3050

\begin{tabular}{lcccccccccccc}
\hline Extratores & Estatística & $\mathrm{K}$ & $\mathrm{Na}$ & $\mathrm{Cu}$ & $\mathrm{Ca}$ & $\mathrm{Mg}$ & $\mathrm{Mn}$ & $\mathrm{Zn}$ & $\mathrm{Cd}$ & $\mathrm{Fe}$ \\
\hline & média & 3,53 & 5,21 & 0,008 & 2,08 & 0,63 & 0,78 & 0,08 & 0,13 & 0,22 \\
$\mathrm{H}$ & mínimo & 0,26 & $<0,012$ & $<0,007$ & 0,10 & 0,01 & $<0,052$ & $<0,018$ & $<0,0028$ & $<0,011$ \\
& máximo & 9,37 & 15,77 & 0,04 & 5,61 & 1,81 & 2,94 & 0,33 & 0,37 & 0,70 \\
& Desvio Padrão & 2,39 & 4,35 & 0,02 & 1,84 & 0,55 & 1,13 & 0,12 & 0,16 & 0,25 \\
& média & 3,10 & 4,49 & $<0,007$ & 34,11 & 8,09 & 1,99 & 0,10 & 0,28 & 1,26 & 0,28 \\
& mínimo & 0,06 & $<0,012$ & $<0,007$ & 3,22 & 1,08 & 0,23 & 0,02 & $<0,0028$ & 0,07 \\
$\mathrm{CH}_{3} \mathrm{COONH}_{4}$ & máximo & 4,93 & 18,10 & $<0,007$ & 80,28 & 15,71 & 3,81 & 0,37 & 0,91 & 6,67 \\
& Desvio Padrão & 1,67 & 6,04 & $<0,007$ & 24,22 & 4,81 & 1,45 & 0,11 & 0,32 & 2,20 \\
& média & 0,75 & 42,49 & 0,16 & $<0,092$ & 27,19 & 0,29 & 0,36 & 0,01 & 298,48 \\
& mínimo & $<0,04$ & 14,39 & $<0,007$ & $<0,092$ & 15,97 & $<0,052$ & 0,07 & $<0,0028$ & 137,71 \\
& máximo & 4,57 & 57,17 & 0,31 & $<0,092$ & 46,36 & 3,15 & 0,60 & 0,05 & 392,07 \\
& Desvio Padrão & 1,49 & 14,18 & 0,11 & $<0,092$ & 7,55 & 0,90 & 0,17 & 0,01 & 89,20 \\
\hline
\end{tabular}

Tabela 4. Percentagem do metal solúvel (extraído com água ultrapura) em relação ao residual (extraído pelo procedimento USEPA-3050) nas amostras de sedimento

\begin{tabular}{|c|c|c|c|c|c|c|}
\hline Amostragem & Pontos & $\mathrm{Cu}(\%)$ & $\mathrm{Zn}(\%)$ & $\mathrm{Fe}(\%)$ & $\operatorname{Mn}(\%)$ & $\mathrm{Cd}(\%)$ \\
\hline \multirow{3}{*}{ Período seco } & P5 & $<0,08$ & $<0,8$ & $<0,1$ & $<0,5$ & $<0,028$ \\
\hline & P6 & $<0,08$ & $<0,8$ & $<0,1$ & $<0,5$ & $<0,028$ \\
\hline & P7 & $<0,08$ & $<0,8$ & $<0,1$ & $<0,5$ & $<0,028$ \\
\hline \multirow{5}{*}{ Período chuvoso } & $\mathrm{P} 2$ & 23,26 & 23,41 & $<0,1$ & 17,92 & 54,54 \\
\hline & P3 & 100 & 78,57 & 0,12 & 34,53 & 52,82 \\
\hline & $\mathrm{P} 4$ & 100 & 100 & 0,36 & 60,51 & 78,94 \\
\hline & P5 & 2,64 & 100 & 0,35 & 66,40 & 60,78 \\
\hline & P6 & 100 & 7,12 & 0,32 & 82,54 & 68,51 \\
\hline \multirow{4}{*}{ Final período chuvoso } & P3 & $<0,08$ & $<0,8$ & $<0,1$ & $<0,5$ & $<0,028$ \\
\hline & $\mathrm{P} 4$ & $<0,08$ & $<0,8$ & $<0,1$ & $<0,5$ & $<0,028$ \\
\hline & P6 & $<0,08$ & $<0,8$ & $<0,1$ & $<0,5$ & $<0,028$ \\
\hline & P7 & $<0,08$ & $<0,8$ & $<0,1$ & $<0,5$ & $<0,028$ \\
\hline
\end{tabular}

realizou-se o auto-escalonamento dos dados brutos, de modo que cada variável apresentasse média zero e variância igual a um. Na sequiência, utilizaram-se as análises fatoriais, com rotação varimax para reduzir a contribuição de variáveis menos significativas, minimizando a estrutura dos dados obtidos da PCA.

A PCA foi obtida a partir de uma matriz de dados previamente normalizada, formada pelos valores das concentrações de $\mathrm{Na}, \mathrm{K}, \mathrm{Ca}$, $\mathrm{Mg}, \mathrm{Mn}, \mathrm{Cu}, \mathrm{Zn}, \mathrm{Cd}$ e Fe determinadas nas frações solúveis, disponíveis e residuais das amostras de sedimento coletadas em 3 períodos: período seco (outubro de 2005), final do período chuvoso (abril de 2006) e período chuvoso (novembro de 2006) em pontos distribuídos na zona rural e urbana do Córrego Verruga. Foram selecionadas duas componentes derivadas por rotação varimax.

A distribuição das frações dos sedimentos em relação às componentes 1 e 2 é mostrada na Figura 5. Pode-se distinguir claramente a formação de três grupos bem definidos: um grupo formado unicamente pelas frações residuais dos sedimentos (extraídos pelo procedimento USEPA-3050) e outros dois grupos formados pelas frações solúveis e disponíveis (extraídos com água ultrapura e acetato de amônio, respectivamente). Para esses dois últimos grupos, localizados no lado negativo da componente 1 , ficou evidente que a variação sazonal das amostras de sedimento influenciou na separação dos agrupamentos ao longo da componente 2, conforme mostra a Figura 5. Desta forma, a primeira componente distingue o nível de disponibilidade dos íons metálicos nos sedimentos e a segunda componente permite a discriminação dos dois agrupamentos formados pelas frações solúveis e disponíveis: o agrupamento das amostras coletadas no período seco e no início da estação chuvosa (out/2005 e nov/2006, respectivamente) e o agrupamento das amostras coletadas no final da estação chuvosa, período onde se processam a adubação dos selos agrícolas (abril/2006). ${ }^{25-30}$

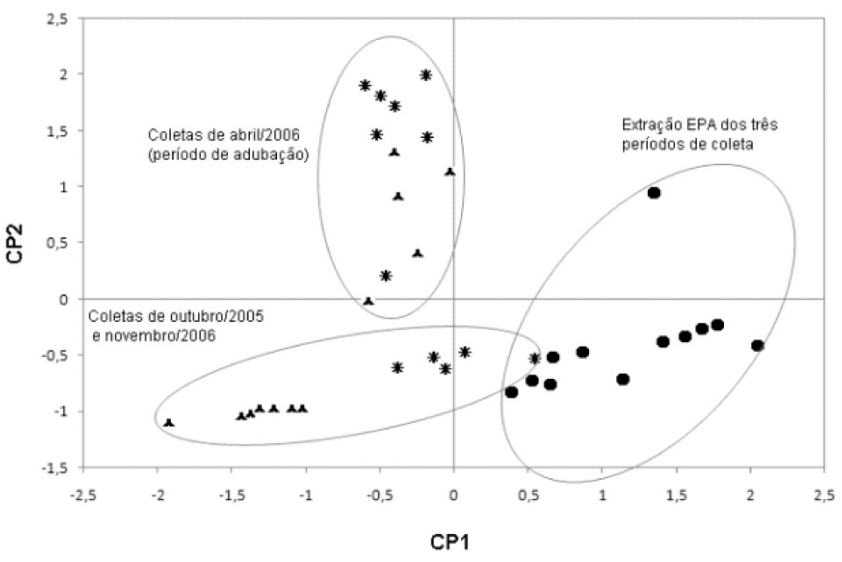

Figura 5. Resultados da análise de componentes principais mostrando o gráfico dos scores das frações extraídas dos sedimentos coletados no Córrego Verruga (CP1 x CP2): fração solúvel em água (\); fração extraída com $\mathrm{CH}_{3} \mathrm{COONH}_{4}(*)$; fração residual $(\bullet)$ 
O gráfico de loadings (Figura 6) permite a caracterização de tendências entre as variáveis. Observa-se ao longo do eixo da CP1 que as variáveis $\mathrm{Na}, \mathrm{Mg}, \mathrm{Fe}, \mathrm{Zn}, \mathrm{Cu}$ e $\mathrm{Ni}$ influenciam diretamente as faixas sustentáveis (valores positivos). A CP2 diferencia os agrupamentos das espécies que indicam a variação sazonal das frações solúveis e disponíveis dos sedimentos. Pode-se notar, ao longo do eixo da CP2, que as variáveis que mais contribuem para a diferenciação dos agrupamentos das amostras de sedimento coletadas em abril de 2006 (valores positivos na CP2) são Cd, Mn, Ca e K. Estes elementos indicam o aumento da disponibilização dos metais provocado pela adubação das áreas de produção agrícola, que normalmente ocorre nos meses de março e abril.

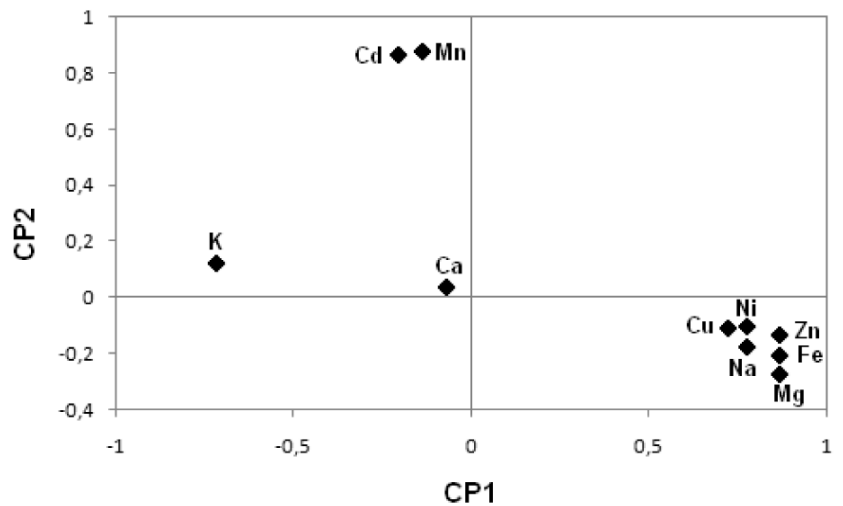

Figura 6. Comportamento das variáveis em relação às primeiras duas componentes principais

\section{CONCLUSÕES}

O estudo indica que a nascente do Córrego Verruga encontra-se protegida, devido à estabilidade das concentrações dos parâmetros observados, mesmo em períodos chuvosos. As variações das concentrações dos parâmetros estudados nos pontos P2 ao P6 podem ser atribuídas aos aportes de esgotos sanitários e drenagem de águas pluviais urbanas e resíduos provenientes das atividades agropecuárias. Observa-se que no ponto $\mathrm{P} 7$, através dos parâmetros analisados pela PCA, embora tenham ocorrido variações sazonais, a estabilidade se mantém devido à aeração provocada pelo desnível dos pontos anteriores, favorecendo a autodepuração das águas do Córrego Verruga.

A técnica de componentes principais constituiu-se em valiosa ferramenta que permite identificar tendências ou características de diferentes processos da hidroquímica de córregos que percorrem áreas urbanas e rurais. A contribuição mais importante da PCA neste estudo foi a identificação de parâmetros que governam a mobilização de $\mathrm{Na}, \mathrm{K}, \mathrm{Ca}, \mathrm{Mg}, \mathrm{Mn}, \mathrm{Cu}, \mathrm{Zn}, \mathrm{Cd}$ e Fe nos percursos urbano e rural do Córrego Verruga. Esta caracterização é de grande importância para estabelecer diretrizes na administração dos recursos hídricos e na melhoria da qualidade das águas

\section{REFERÊNCIAS}

1. Göbel, P.; Dierkes, C.; Coldewey, W. G.; J. Contam. Hydrol. 2007, 91, 26.

2. Chalmers, A. T.; Van Metre, P. C.; Callender, E.; J. Contam. Hydrol. 2007, 91,4

3. Ellis, P. A.; Mackay, R.; Rivett, M. O.; J. Contam. Hydrol. 2007, 91, 58.

4. Mahler, B.; Massei, N.; J. Contam. Hydrol. 2007, 91, 81.

5. Felipe-Sotelo, M.; Andrade, J. M.; Carlosena, A.; Tauler, R.; Anal. Chim. Acta 2007, 583, 128

6. Raiswell, R. W.; Brimblecambe, P.; Dent, D. L.; Liss, P. S.; Environmental Chemistry, Ediciones Omega: Barcelona, 1983.

7. Lu, X. Q.; Werner, I.; Young, T. M.; Environ. Int. 2005, 31, 593.

8. Drever, J. I.; The Geochemistry of Natural Waters: Surface and Groundwater environments, $3^{\text {rd }}$ ed., Prentice Hall: Englewood Cliffs, 1997.

9. Boiley, R. A.; Clark, H. M.; Ferris, J. P.; Krause, S.; Strang, R. L.; Chemistry of the Environment, Academic Press: New York, 1978.

10. Nguyen, H. L.; Leermakers, M.; Osán, J.; Török, S.; Baeyens, W.; Sci. Total Environ. 2005, 340, 213.

11. Morel, F. M. M.; Hering, J. G.; Principles and Applications of Aquatic Chemistry, John Wiley: New York, 1993.

12. Gaur, V. K.; Gupta, S. K.; Pandey, S. D.; Gopal, K.; Misra, V.; Environ. Monit. Assess. 2005, 102, 419

13. Filgueiras, A. V.; Lavilla, I.; Bendicho, C.; Sci. Total Environ. 2004, 330, 115 .

14. Caplat, C.; Texier, H.; Barillier, D.; Lelievre, C.; Mar. Pollut. Bull. 2005, $50,504$.

15. Fangueiro, D.; Bermond, A.; Santos, E.; Carapuça ${ }_{s}$ H.; Duarte, A.; Talanta 2005, 66, 844 .

16. Santos, J. S.; Oliveira, E.; Bruns, R. E.; Gennari, R. F.; Water Res. 2004, $38,1579$.

17. Santos, J. S.; Oliveira, E.; Massaro, S.; Quim. Nova 2000, 23, 453.

18. Bloom, N. S.; Preus, E.; Katon, J.; Hiltner, M.; Anal. Chim. Acta 2003, 479, 233.

19. Davidson, C. M.; Urquhart, G. J.; Ajmone-Marsan, F.; Biasioli, M.; Duarte, A. C.; Diáz-Barrientos, E.; Grcman, H.; Hossack, I.; Hursthouse, A. S.; Madrid, L.; Rodrigues, S.; Zupan, M.; Anal. Chim. Acta 2006, 565, 63 .

20. Lima, M. C.; Giacomelli, M. B. O.; Stüpp, V.; Roberge, F. D.; BermejoBarrera, P.; Quim. Nova 2001, 24, 734.

21. Nguyen, H. L.; Leermakers, M. L.; Elskens, M.; De Ridder, F.; Doan, T. H., Baeyens, W.; Sci. Total Environ. 2005, 341, 211.

22. Sena, M. M.; Poppi, R. J.; Frighetto, R. T. S.; Valarini, P. J.; Quim. Nova 2000, 23, 547.

23. Soares, H. M. V. H.; Boaventura, R. A. R.; Machado, A. A. S. C.; Esteves da Silva, J. C. G.; Environ. Pollut. 1999, 105, 311.

24. Correia, P. R. M.; Ferreira, M. M. C.; Quim. Nova 2007, $30,481$.

25. Westall, J.; Stumm, W.; The Natural Environment and the Biogeochemical Cycles. The Hydrosphere, Springer: New York, 1984.

26. Perona, E.; Bonilla, I.; Mateo, P.; Sci. Total Environ. 1999, 241, 75.

27. Bricker, S. B.; Sci. Total Environ. 1996, 179, 27.

28. Surija, B.; Branica, M.; Sci. Total Environ. 1995, 170, 101.

29. Mihelcic, G.; Surija, B.; Juracic, M.; Barisic, D.; Branica, M.; Sci. Total Environ. 1996, 182, 105

30. Wen, X.; Allen, H. E.; Sci. Total Environ. 1999, 227, 101. 